\title{
Technology Licensing and Shareholding in Vertically-Related Markets
}

\author{
Jun-Yen $\mathrm{Wu}^{1^{*}}$, Hong-Ren Din ${ }^{2}$ \\ ${ }^{1}$ Department of Business Administration, TransWorld University, Douliu, Taiwan \\ ${ }^{2}$ Department of Tourism and Hospitality, TransWorld University, Douliu, Taiwan \\ Email: ${ }^{\text {junyenwu@twu.edu.tw }}$
}

Received 23 February 2015; accepted 12 March 2015; published 17 March 2015

Copyright (C) 2015 by authors and Scientific Research Publishing Inc.

This work is licensed under the Creative Commons Attribution International License (CC BY). http://creativecommons.org/licenses/by/4.0/

(c) (i) Open Access

\begin{abstract}
This paper explores the optimal licensing contract, in which the manufacture firm holds the equity of the retail firm and licenses the cost-reducing innovation to the vertically integrated firm. The objective of this paper is to investigate the effect of the retail firm's equity on the manufacture firm's licensing decisions. The paper shows that the manufacture firm prefers royalty (fixed-fee) licensing when the manufacture firm holds large (small) equity of the retail firm.
\end{abstract}

Keywords

Vertically Related Markets, Fixed-Fee and Royalty Licensing, Two-Part Tariff

\section{Introduction}

This paper aims to explore an issue relating to the vertically related markets, where an upstream manufacture firm holds equity with a downstream retail firm and licenses a cost-reducing technology to a vertically integrated firm. What is the manufacture firm's optimal licensing contract in terms of fixed-fee, royalty or two-part tariff licensing?

There is a vast literature discussing the optimal licensing contract, where the innovation is licensed from the outsider. For example, Kamien and Tauman, Katz and Shapiro and Kamien et al. [1]-[4] show that licensing an innovation by means of a royalty is less profitable than it by means of a fixed fee under Cournot competition. Muto [5], Poddar and Sinha [6] show that offering a royalty licensing is the best contract for small innovations when products are close substitutes. While Wang [7] and Kamien and Tauman (2002), among others, show that an insider patentee always prefers a royalty to a fixed-fee contract if the products produced by the licensor and the licensee are homogeneous.

\footnotetext{
${ }^{*}$ Corresponding author.
} 
However, there exists sparse literature which focuses on the subject that a manufacture firm holds the equity of a retail firm and licenses innovation to the vertically integrated firm. When the manufacture firm holds all the equity, then it owns the retail firm completely; this acts like an insider patentee. On the contrary, the manufacture firm doesn't hold the equity and then it acts like an outsider patentee. When the manufacture firm holds the equity, it could be both an insider patentee and an outsider patentee. The objective of this paper is to investigate the effect of the equity of the retail firm on the manufacture firm's licensing decisions. The major findings are as follows. The manufacture firm prefers royalty (fixed-fee) licensing when the manufacture firm holds large (small) equity of the retail firm.

The remainder of this paper is organized as follows. Section 2 sets out a basic model without licensing. Section 3 examines the licensing contract under two-part tariff contract. Section 4 concludes the paper.

\section{The Basic Framework}

Consider a framework consisting of one manufacture firm, firm 1, one retail firm, firm 2, and one vertically integrated firm, firm 3. Firm 1 and 3 produce a homogenous good. Firm 1 sells productions through firm 2 and firm 3 sells productions himself. In the retailing market, firm 2 and 3 engage in a Cournot competition. Firm 1 owns an innovation, which can reduce the marginal cost of firm 3 by the amount $\varepsilon$, where $0<\varepsilon \leq c$. Let us consider the general licensing scheme involving both a fixed fee and a linear royalty per unit of output, i.e. two-part tariff licensing. Note that fixed-fee only or royalty only licensing are special cases of this generalized licensing scheme.

Assume that the inverse demand function is a linear function denoted by $p=a-q_{2}-q_{3}$, where $a$ is the constant reservation price, $q_{2}\left(q_{3}\right)$ is the output of firm 2 (3) and $p$ is the market price. Moreover, we also assume the manufacturer firm holds a fractional equity interest $\beta$ with the retail firm, where $0 \leq \beta \leq 1$. In other words, firm 1 receives a fraction $\beta$ of firm 3's profit. Note that if the $\beta$ approaches one, then the manufacturer completely owns the retail firm, this act as an insider patentee. On the contrary, when manufacture firm doesn't hold the equity (i.e., $\beta=0$ ) and then it acts as an outsider patentee.

Consider a general model where the superscript of each variable, $i=\{N, T\}$, denotes the cases where the technology licensing is absent and licensing is by means of two-part tariff licensing contract, respectively. The game in question is a three-stage game. In the first stage, the manufacturer selects an optimal contract and the wholesale price. In the second stage, firm 3 decides whether to accept or reject the offer made by firm 1 . If firm 3 is not worse off, it will accept the contract. In the final stage, given the type of contract and the wholesale price, firm 2 and firm 3 engage in Cournot competition in the retailing market. We derive the sub-game perfect equilibrium by backward induction beginning with the final stage.

In the final stage, firm 2 and firm 3 play Cournot competition. Firm 1 holds a fractional equity interest $\beta$ with firm 2, so that firm 2 receives the remaining fraction $(1-\beta)$ of its profit. The profit function of firm 2 and firm 3 are as follows:

$$
\begin{gathered}
\pi_{2}^{i}=(1-\beta)(p-w) q_{2} \\
\pi_{3}^{i}=\left(p-c^{i}\right) q_{3}
\end{gathered}
$$

where the superscript $i=\{N, T\}$ and $w$ is the wholesale price.

Substituting the inverse demand function into (1), and then differentiating (1) with respect to $q_{2}$ and $q_{3}$ respectively, we can have the first-order conditions. Simultaneous solving the first-order conditions, we can get the output of firm 2 and firm 3 as follows:

$$
\begin{aligned}
& q_{2}^{i}=\left(a-2 w+c^{i}\right) / 3, \quad i=N, T, \\
& q_{3}^{i}=\left(a+w-2 c^{i}\right) / 3, \quad i=N, T .
\end{aligned}
$$

Substituting (2) into (1), the profit function of firm 2 and firm 3 can be rewritten as:

$$
\begin{gathered}
\pi_{2}^{i}=(1-\beta)\left(a-2 w+c^{i}\right)^{2} / 9, \quad i=N, T, \\
\pi_{3}^{i}=\left(a+w-2 c^{i}\right)^{2} / 9, \quad i=N, T .
\end{gathered}
$$


For the case where technology licensing is absent, substituting $c^{N}=c$ into (2) and (3), the output and the profit for firm 2 and firm 3 can be derived as follows:

$$
\begin{gathered}
q_{2}^{N}=(a-2 w+c) / 3, \text { and } q_{3}^{N}=(a+w-2 c) / 3, \\
\pi_{2}^{N}=(1-\beta)(a-2 w+c)^{2} / 9, \text { and } \pi_{3}^{N}=(a+w-2 c)^{2} / 9 .
\end{gathered}
$$

In the first stage, manufacture firm determines the wholesale price. The profit function of manufacture firm is as follows:

$$
\pi_{1}^{N}=(w-c+\varepsilon) q_{2}^{N}+\beta \pi_{2}^{N} .
$$

Differentiating (5) with respect to $w$, we obtain:

$$
\partial \pi_{1}^{N} / \partial w=\underbrace{(a+c-2 w) / 3}_{\text {the output effect }(+)} \underbrace{-2(w-c+\varepsilon) / 3}_{\text {the indirect effect }(-)} \underbrace{-4 \beta(a+c-2 w) / 9}_{\text {the equity effect( }(-)}
$$

The first term on the right-hand side of (6) is positive, the second term is negative, while the third term is non-positive. These three terms are referred to as the output effect, the indirect effect and the equity effect. The optimal wholesale price is jointly determined by these three effects. Intuitively, the output effect shows that as retail firm's output increases, the manufacture firm raises the wholesale price in order to earn larger profit. Next, the indirect effect shows that a rise in wholesale price decreases the retail firm's output. Thus, the manufacture firm increases the retail firm's output by lowering its wholesale price. Lastly, the equity effect decreases the wholesale price. The equity effect emerges because the manufacture firm's profit includes his own profit and the retail firm's profit. A rise in the equity $\beta$ implies that the manufacture firm cares more about retail firm's profit. This equity effect induces the manufacture firm to increase the retail firm's profit by lowering its wholesale price. In sum, the optimal wholesale price hinges upon the relative strength of these three effects.

Solving (6), we can have the optimal wholesale price as follows:

$$
w=[3(a+3 c-2 \varepsilon)-4 \beta(a+c)] /[4(3-2 \beta)] .
$$

Equation (7) shows that a rise in the equity which held by the manufacture firm decreases the optimal wholesale price. The higher the equity held by the manufacture, the stronger will be the equity effect. From Equation (6), it follows that as the equity $\beta$ increases, the equity effect dominates the output effect then the wholesale price decreases. Thus, we can establish the following lemma 1.

Lemma 1. Suppose that the manufacture firm holds the fractional equity interest $\beta$ in the retail firm. The increase in the equity $\beta$ decreases the optimal wholesale price.

Substituting (7) into (4) and (5), the equilibrium profits of the firms are as follows:

$$
\begin{gathered}
\pi_{1}^{N}=(3-4 \beta)(a-c+2 \varepsilon)^{2} / 8(3-2 \beta)^{2}+\beta(a-c+2 \varepsilon)^{2} / 4(3-2 \beta)^{2} \\
\pi_{2}^{N}=(1-\beta)(a-c+2 \varepsilon)^{2} / 4(3-2 \beta)^{2} \\
\pi_{3}^{N}=[5 a-5 c-2 \varepsilon-4 \beta(a-c)]^{2} / 16(3-2 \beta)^{2}
\end{gathered}
$$

\section{Two-Part Tariff Licensing}

In this section, we explore the optimal licensing in the case where manufacture firm licenses a cost-reducing technology to the vertically integrate firm by means of a two-part tariff licensing in the first stage.

Substituting the marginal cost under two-part tariff licensing, $c^{T}=c-\varepsilon+r$ where $r$ denotes royalty rate, into (2) and (3), we can derive the equilibrium output and the equilibrium profit for firm 2 and firm 3 as follows:

$$
\begin{gathered}
q_{2}^{T}=(a-2 w+c-\varepsilon+r) / 3, \quad \text { and } q_{3}^{T}=[a+w-2(c-\varepsilon+r)] / 3, \\
\pi_{2}^{T}=(1-\beta)(a-2 w+c-\varepsilon+r)^{2} / 9, \quad \text { and } \pi_{3}^{T}=\left[a+w-2(c-\varepsilon+r)^{2}\right] / 9 .
\end{gathered}
$$

In the second stage, firm 3 decides whether to accept or reject the contract made by the manufacture firm. 
Following related literature, assume that firm 3 accepts the contract if it receives a weakly greater profit from acceptance than from rejection, i.e., $\pi_{3}^{T}-F \geq \pi_{3}^{N}$, where $F$ denotes the fixed-fee. Therefore, firm 3's maximal willingness to pay for the innovation as follows:

$$
F=\pi_{3}^{T}-\pi_{3}^{N}=\left[a+w-2(c-\varepsilon+r)^{2}\right] / 9-\left[a+w-2(c-\varepsilon)^{2}\right] / 9
$$

In the first stage, the manufacture firm determines the optimal wholesale price and the optimal royalty rate. The manufacture firm licenses a cost-reducing innovation to the vertically integrated firm, so firm 1's profit includes its operating profit, a portion of the retail firm's profit and the licensing revenue. Thus the manufacture firm's profit can be described as follows:

$$
\begin{array}{ll}
\max _{r, w} & \pi_{1}^{T}=(w-c+\varepsilon) q_{2}^{T}+\beta \pi_{2}^{T}+r q_{3}^{T}+F, \\
\text { s.t. } & \pi_{3}^{T}-F \geq \pi_{3}^{N} .
\end{array}
$$

Differentiating (11) with respect to $w$ and $r$ respectively, we obtain:

$$
\begin{gathered}
\partial \pi_{1}^{T} / \partial w=\underbrace{(a+c-\varepsilon+r-2 w) / 3}_{\text {the output effect }(+)} \underbrace{-2(w-c+\varepsilon) / 3}_{\text {the indirect effect }(-)} \underbrace{-4 \beta(a+c-\varepsilon+r-2 w) / 9}_{\text {the equity effect }(-)}+\underbrace{+(4 \varepsilon-r) / 9}_{\text {the licensing revenue effect (+) }} \\
\partial \pi_{1}^{T} / \partial r=\underbrace{(w-c+\varepsilon) / 3}_{\text {the protection effect }(+)} \underbrace{+2 \beta(a+c-\varepsilon)}_{\text {the equity effect }(+)} \underbrace{-[a-2 w) / 9-2(c-\varepsilon+r)+w+6 r] / 9}_{\text {the efficiency effect }(-)}
\end{gathered}
$$

These four terms on the right-hand side of (12.1) are referred to as the output effect, the indirect effect, the equity effect and the licensing revenue effect, in that order. The first three effects are identical to that in eq. (7). However, the manufacture firm licenses its innovation to the vertically integrated firm; there is an extra effect to determine the wholesale price, i.e. the licensing revenue effect. This effect can increase the wholesale price and then firm 3 earns more profit. Firm 1 can extract the entire extra firm 3's benefits by licensing via charging a fixed-fee and royalty rate. Consequently, these four effects jointly determine the optimal wholesale price.

The first and second terms on the right-hand side of (12.2) are positive, while the third term is negative. These three terms are referred to as the protection effect, the equity effect and the efficiency effect. The protection effect reflects the fact that the manufacture firm can increase its operating profit by raising the royalty rate, i.e., by increasing firm 3's marginal cost. Next, a rise in the equity effect increases the royalty rate. This is because the manufacture firm can raise a retail firm's profit by increasing marginal cost of the vertically integrated firm. Thirdly, the efficiency effect indicates that firm 3's output and then its profit increases by decreasing the royalty rate to enhance the firm 3's production efficiency. Consequently, the protection effect and the equity effect attract the patentee to raise the royalty rate, while the efficiency effect gives rise to the opposite effect. The optimal royalty rate hinges upon the relative strength of these three effects.

Solving (12.1) and (12.2) simultaneously, the equilibrium wholesale price and royalty rate are as follows:

$$
\begin{gathered}
w=[5 a+17 c-9 \varepsilon-\beta(7 a+13 c-9 \varepsilon)] / 2(11-10 \beta) \\
r=(2 \beta-1)(3 a-3 c-\varepsilon) / 2(11-10 \beta)
\end{gathered}
$$

Now depending on the parameter configurations, we have the following three distinct possibilities under two-part tariff licensing contract. These possibilities arise owing to the constraints $r \geq 0$ and $r \leq \varepsilon$.

$$
r= \begin{cases}0, & \beta \leq \frac{1}{2} ; \\ \frac{(2 \beta-1)(3 a-3 c-\varepsilon)}{2(11-10 \beta)}, & \frac{1}{2}<\beta<\frac{a-c+7 \varepsilon}{2(a-c+3 \varepsilon)} ; \\ \varepsilon & \beta \geq \frac{a-c+7 \varepsilon}{2(a-c+3 \varepsilon)} .\end{cases}
$$

It is interesting to note that when the royalty rate equals zero, the manufacture firm would charge a fixed-fee, when the manufacture firm holds small equity of the retail firm. When $\beta$ is large then only royalty licensing is 
charged. However, when $\beta$ is at intermediate level, we find the existence of a two-part tariff as the optimal licensing contract. The intuition is as follows. Equation (12.2) shows that the optimal royalty rate hinges upon the relative strength of these three effects. The larger the equity held by the manufacture, the stronger will be the equity effect. It follows that the equity effect and the protection effect dominates the efficiency effect, such that royalty rate will increase. In other words, the manufacture firm's profit includes its operating profit, a portion of the retail firm's profit and licensing revenue. If $\beta$ is large, then the manufacture firm emphasize the retail firm's profit by increasing firm 3's marginal cost i.e., by increasing the royalty rate. Based on the above analysis, we establish:

Proposition 1. Assume that the manufacture firm holds the fractional equity interest $\beta$ in the retail firm. The manufacture firm's optimal licensing contract is pure royalty (fixed-fee) licensing when the equity $\beta$ is relatively large (small). For $\beta$ is intermediate, the optimal contract consists of both royalty rate and fixed-fee.

Kamien and Tauman (1986), Katz and Shapiro $(1985,1986)$ and Kamien et al. (1992) show that when the innovator is an outsider, fixed-fee licensing is superior to royalty licensing. This result is similar to the case where the equity $\beta$ is relatively small. On the other hand, Wang (1998) and Kamien and Tauman (2002) show that when the innovator is an insider, royalty licensing is superior to fixed-fee licensing. This result is similar to the case where the equity $\beta$ is relatively larger. Therefore, Proposition 1 bridges the gap between optimal licensing contracts for insider and outsider patentees.

\section{Concluding Remarks}

This paper has developed a two-stage model, in which the manufacture firm holds the fractional equity interest $\beta$ in the retail firm and licenses the innovation to the vertically integrated firm. We show that the manufacture firm prefers royalty (fixed-fee) licensing, as the equity $\beta$ is large (small). While $\beta$ is at intermediate level we find the existence of a two-part tariff as the optimal licensing contract.

\section{References}

[1] Kamien, M. and Tauman, Y. (1986) Fees versus Royalties and the Private Value of a Patent. Quarterly Journal of Economics, 101, 471-491. http://dx.doi.org/10.2307/1885693

[2] Kamien, M.I., Oren, S.S. and Tauman, Y. (1992) Optimal Licensing of Cost-Reducing Innovation. Journal of Mathematical Economics, 21, 483-508. http://dx.doi.org/10.1016/0304-4068(92)90036-7

[3] Katz, M. and Shapiro, C. (1985) On the Licensing of Innovations. The RAND Journal of Economics, 16, 504-520. http://dx.doi.org/10.2307/2555509

[4] Katz, M. and Shapiro, C. (1986) How to License Intangible Property. Quarterly Journal of Economics, 101, 567-590. http://dx.doi.org/10.2307/1885697

[5] Muto, S. (1993) On Licensing Policies in Bertrand Competition. Games and Economic Behavior, 5, 257-267. http://dx.doi.org/10.1006/game.1993.1015

[6] Poddar, S. and Sinha, U.B. (2004) On Patent Licensing in Spatial Competition. Economic Record, 80, 208-218. http://dx.doi.org/10.1111/j.1475-4932.2004.00173.x

[7] Wang, X.H. (1998) Fee versus Royalty Licensing in a Cournot Duopoly Model. Economics Letters, 60, 55-62. http://dx.doi.org/10.1016/S0165-1765(98)00092-5 